ISSN 0103-9954

\title{
CARACTERÍSTICAS DA LENHA PRODUZIDA NA REGIÃO DA QUARTA COLÔNIA DE IMIGRAÇÃO ITALIANA DO RIO GRANDE DO SUL
}

\section{CHARACTERISTICS OF THE FIREWOOD PRODUCED IN THE REGION OF THE FOURTH COLONY OF ITALIAN IMMIGRATION OF RIO GRANDE DO SUL}

\author{
Darci Alberto Gatto ${ }^{1}$ Elio José Santini ${ }^{2}$ Clovis Roberto Haselein ${ }^{3}$ Miguel Antão Durlo ${ }^{4}$
}

\begin{abstract}
RESUMO
Este estudo foi conduzido com o objetivo de avaliar a qualidade da lenha produzida na Região da Quarta Colônia de Imigração Italiana no Rio Grande do Sul, levando-se em conta o fator de conversão de estéreo para $\mathrm{m}^{3}$, o teor de umidade, massa específica básica e o poder calorífico da madeira. $\mathrm{O}$ fator médio de conversão, importante para a estimativa do volume sólido, foi de 0,61 e 0,56 respectivamente para eucalipto e nativas. A massa específica básica encontrada para a lenha foi de $0,44 \mathrm{~g} / \mathrm{cm}^{3}$ para eucalipto e $0,46 \mathrm{~g} / \mathrm{cm}^{3}$ para nativas, classificando-as como madeiras levemente densas. O poder calorífico estimado para a umidade de equilíbrio média da região foi 1915 e $2002 \mathrm{Kwh} / \mathrm{m}^{3}$ respectivamente para a lenha de eucalipto e de nativas, mas em torno de $13,6 \%$ desse valor é perdido, porque a lenha é queimada com um teor de umidade médio de $32 \%$. Esses resultados indicam a necessidade de maiores cuidados com o empilhamento e a secagem da lenha visando a diminuição da perda de energia com a queima de material úmido.
\end{abstract}

Palavras-chave: massa especifica básica, fator de conversão, lenha, umidade.

\begin{abstract}
This research was carried out with the objective of evaluating the firewood quality produced in the $4^{\text {th }}$ Colony of Italian Immigration of Rio Grande do Sul taking into account the conversion factor from stacked to cubic meter, moisture content, basic density and fuel value of the wood. The conversion factor, important in estimating the solid volume, ranged from 0,61 for eucalypt wood to 0,56 for native species. The wood basic density found for eucalypt was $0,44 \mathrm{~g} / \mathrm{cm}^{3}$ compared to $0,46 \mathrm{~g} / \mathrm{cm}^{3}$ for native species, assorting them as slightly dense wood. The estimated heat of combustion for the wood equilibrium moisture content of the region was 1915 and $2002 \mathrm{kwh} / \mathrm{m}^{3}$, respectively, for eucalypt and native firewood. However, 13,6\% of these values are lost because the wood is burned with an average moisture content of $32 \%$. These results indicate the need of a more careful stacking and drying of the firewood, what would lead to a decrease in energy losses that happens when moist material is burnt.
\end{abstract}

Key words: Basic density, cubic scaling, firewood, moisture content.

\section{INTRODUÇÃO}

Para o agricultor, a lenha é o principal produto energético, utilizado para cozimento dos alimentos ou secagem de grãos. No Brasil, a lenha também é utilizada como combustível industrial, sustentando a indústria siderúrgica que embasa sua produção em carvão vegetal. No sul do País, as agroindústrias utilizam a lenha como base energética para a produção de vapor, indispensável em seus processos industriais. Já no Uruguai, numerosas indústrias têm suas caldeiras funcionando mediante a queima direta ou a gaseificação para produzir vapor d'água ou eletricidade. No Chile, grande parte das indústrias de celulose e papel utilizam resíduos florestais e lenha como combustível para suas caldeiras(FAO, 1987).

Na Região da Quarta Colônia, onde se desenvolveu este trabalho, foi consumido no ano de 1999 um montante de $4.679 \mathrm{~m}^{3}$ lenha, utilizada nas olarias, na secagem de grãos e fábricas de queijo (Gatto, 2002).

1. Engenheiro Florestal, M.Sc., doutorando do Programa de Pós-graduação em Engenharia Florestal, Centro de Ciências Rurais, Universidade Federal de Santa Maria, CEP 97105-900, Santa Maria (RS).

2. Engenheiro Florestal, Dr., Professor Adjunto do Departamento de Ciências Florestais, Centro de Ciências Rurais, Universidade Federal de Santa Maria, CEP 97105-900,Santa Maria (RS). santinie@,ccr.ufsm.br

3. Engenheiro Florestal, PhD., Professor Adjunto do Departamento de Ciências Florestais, Centro de Ciências Rurais, Universidade Federal de Santa Maria, CEP 97105-900,Santa Maria (RS). haseleic@ccr.ufsm.br

4. Engenheiro Florestal, Dr., Professor Adjunto do Departamento de Ciências Florestais, Centro de Ciências Rurais, Universidade Federal de Santa Maria, CEP 97105-9, Santa Maria (RS). migueldurlo@smail.ufsm.br

Recebido para publicação em 14/04/2003 e aceito em 8/10/200. 
De acordo com FAO (1985), $1 \mathrm{~m}^{3}$ lenha seca ao ar (aproximadamente 15\% de umidade) produz em torno de 10 GJ de energia. Sabe-se também que aumentando o teor de umidade, maior será o gasto de energia para secar a lenha no momento da queima e menor o rendimento de energia produzido por um $\mathrm{m}^{3}$. Conseqüentemente, o melhor aproveitamento da lenha será atingido quando esta tiver a menor porcentagem de umidade.

O volume empilhado é bastante utilizado no Brasil para a comercialização de madeira na indústria de celulose, na produção de chapas e para fins energéticos (carvão e lenha). Apesar dessa utilização, na atualidade, não se tem um fator de conversão para as diferentes regiões e espécies o que induz a uma imprecisão no verdadeiro volume de madeira consumida na indústria e, sobretudo, pelos agricultores. Um exemplo disso é o volume anual médio de $30 \mathrm{~m}^{3}$ de madeira consumido pelos agricultores do município de Ivorá, RS (Pöckl, 2000) cujo alto valor se deve possivelmente às imprecisões de conversão.

Diante desses equívocos de medição, o INMETRO (Instituto Nacional de Metrologia, Normas e Qualidade Industrial), com o apoio da Sociedade Brasileira de Silvicultura (SBS), formaram uma comissão de estudos sobre a utilização da unidade de medida estéreo, com o objetivo de normalizar, para os próximos 10 anos, a utilização do método e estabelecer uma estratégia de mudança e melhoria do sistema de medição no País. A portaria técnica visa a abolir gradualmente a utilização do estéreo, permitindo seu uso até 31 de dezembro de 2009 (IPEF, 1999).

Este trabalho tem como objetivo fazer uma avaliação da qualidade da lenha utilizada para olarias, secagem de produtos agrícolas e outros usos domésticos na Região da Quarta Colônia, com base no fator de conversão de estéreo para $\mathrm{m}^{3}$, no poder calorífico estimado, teor de umidade e massa específica básica.

\section{REVISÃO DE LITERATURA}

A madeira é uma importante fonte renovável de energia. A crise energética que abala o Brasil na atualidade, tende a não ser passageira. O manejo adequado das florestas e o uso racional da madeira como energia podem promover a oferta de energia renovável e de grande qualidade ecológica. Diferente dos derivados de petróleo e carvão mineral, que são fontes esgotáveis de energia e que eliminam na atmosfera, por ocasião da queima, o carbono é armazenado por séculos.

Entretanto, no Brasil, observa-se uma diminuição no consumo de lenha como fonte de energia nos últimos 21 anos. De acordo com Brasil (2000), essa redução se deve à utilização de outras fontes de energia. No período 83-93, houve um aumento do consumo de energia elétrica: $64 \%$ no setor comercial, $60 \%$ no setor público e $149 \%$ no setor agropecuário. No setor residencial houve, no mesmo período, um aumento no consumo de gás liquefeito de petróleo (GLP) em substituição à lenha e um acréscimo de $80 \%$ no consumo da energia elétrica. No entanto, a lenha continua sendo um importante produto primário utilizado no Brasil para a produção de energia.

Um exemplo de consumo médio de lenha no Brasil é o do Rio Grande do Norte estimado em 5,5 st/ano por domicílio e de 925,9 st/ano por empresa (setor industrial/comercial). O consumo total ficou em 5.348.946 st/ano o que representou 102.865 ha de floresta nativa cortada por ano (Zakia et al., 1990).

$\mathrm{O}$ uso da madeira para a geração de energia apresenta algumas vantagens e desvantagens, quando relacionadas a combustíveis à base de petróleo. Entre as vantagens, salientam-se o baixo custo de aquisição, a não-emissão de dióxido de enxofre, menor agressividade das cinzas ao meio ambiente comparadas às provenientes de combustíveis fósseis, a menor corrosão de equipamentos (caldeiras e fornos), o menor risco ambiental por se tratar de recurso renovável, as emissões não contribuem para o efeito estufa e a possibilidade de aproveitamento dos resíduos do processo de fabricação (serragem, cavacos e pedaços de madeira). Como desvantagens podem ser citados: o menor poder calorífico, maior possibilidade de geração de material particulado para a atmosfera e as dificuldades no estoque e armazenamento (Grauer e Kawano, 2001).

A qualidade da madeira para energia está relacionada ao seu teor de umidade e à sua massa específica. Cunha et al. (1989), estudando 55 espécies lenhosas para a geração de energia em caldeiras, concluíram que quanto maior o teor de umidade da madeira, menor é o seu poder de combustão, resultado

Ciência Florestal, v. 13, n. 2, 2003 
do processo de evaporação da água que absorve energia no decorrer da queima. Para Farinhaque (1981), um bom aproveitamento da combustão da madeira se dá com teores de umidade abaixo de $25 \%$. Isso porque a madeira com teores acima de $25 \%$ não só reduz acentuadamente a quantia de calorias, mas também a temperatura da câmara de queima e a temperatura dos gases de escape. Além disso, o excesso de umidade promove a formação de crostas de fuligem nos chaminés e no interior da câmara de combustão.

A importância da madeira como fonte de energia fica evidente quando se tomam os valores citados por Floresta Colonial (2000): um estéreo de madeira seca, aproximadamente $450 \mathrm{~kg}$, é equivalente a 210 litros de óleo combustível que, por sua vez, equivalem a $282 \mathrm{~kg}$ de carvão mineral quanto ao poder calorífico produzido. Esses valores não são fixos, pois a quantidade de energia liberada pela queima da madeira bem como o comportamento da combustão dependem de uma série de fatores, como a composição química, a granulometria, a massa específica básica e o teor de umidade da madeira, além das características das instalações para queimar.

Silva et al. (1984), comparando a biomassa de diferentes espécies para a produção de energia, encontraram, para o Eucalyptus viminalis com teor de umidade de $12 \%$ e peso específico de $0,57 \mathrm{~g} / \mathrm{cm}^{3}$, um poder calorífico de $4.691 \mathrm{kcal} / \mathrm{kg}$ para a madeira e $3.495 \mathrm{kcal} / \mathrm{kg}$ para casca. Já Vale et al. (2000) encontraram, para a Acacia mangium, um poder calorífico superior médio de $4.619 \mathrm{kcal} / \mathrm{kg}$ e para o Eucalyptus grandis $4.641 \mathrm{kcal} / \mathrm{kg}$, não apresentando diferença significativa entre as espécies. No entanto, Maraboto et al. (1989), trabalhando com madeiras de dez espécies nativas da Amazônia, encontraram um poder calorífico superior médio de $4.697 \mathrm{Kcal} / \mathrm{kg}$.

Para cálculos práticos, o poder calorífico inferior da madeira pode ser considerado como 4.500 $\mathrm{Kcal} / \mathrm{kg}$. Esse valor é baseado num teor de umidade a $0 \%$, ou seja, correspondente à madeira absolutamente seca (Nock et al, 1975; Kollmann e Côté, 1968).

Ferreira et al. (1983), pesquisando a variação do teor de umidade da madeira roliça de eucalipto estocada em pátios industriais, concluíram que existe uma variação no teor de umidade da madeira ao longo da alturas das pilhas, sendo maior, quanto mais próxima ao solo. A madeira situada na parte superior das pilhas seca mais rapidamente quando comparada à madeira situada nas camadas mais baixas. $\mathrm{E}$ as maiores taxas de secagem foram verificadas na $1^{-}$semana após o abate. A umidade da madeira tende a valores constantes, a partir da $21^{\mathrm{a}}$ semana após o abate.

À medida que perde umidade, a madeira diminui seu volume. Fernandes et al. (1983), pesquisando a contração volumétrica da madeira roliça de Eucalyptus saligna em estoque para a produção de celulose, concluíram que ocorre uma contração volumétrica a partir do primeiro mês de estoque. Essa redução é crescente por causa da redução do teor de umidade, nos diferentes níveis da pilha. O valor máximo de contração encontrado ficou ao redor de $5 \%$, quando a madeira atinge sua umidade de equilíbrio com o ambiente.

Para a lenha, segundo Günther e Lehmann (1982), o fator de conversão de volume estéreo para $\mathrm{m}^{3}$ varia de 0,60 a 0,65 dependendo da espécie, tortuosidade, comprimento dos toretes, variação do diâmetro dentro da pilha, método de empilhamento (manual ou mecânico). Já Finger (1992) encontrou fatores de conversão variando de 0,52 a 0,71 para toretes de Eucalyptus spp com diâmetro entre 5 a $35 \mathrm{~cm}$.

\section{MATERIAL E MÉTODO}

No período de 17 de maio a 3 de agosto de 2001, foram avaliados 31 pilhas de lenha de Eucalyptus spp e nove pilhas de lenha de espécies nativas na região da Quarta Colônia, prontas para a venda. Foram determinados o fator de conversão do empilhamento, massa específica básica, teor de umidade vendido e de queima, e estimou-se o poder calorífico da madeira.

\section{Fator de conversão}

O fator de conversão do volume em estéreo (st) para volume sólido $\left(\mathrm{m}^{3}\right)$ não é considerado por muitos como um fator de qualidade; todavia, é um dispositivo necessário para quantificar o material com maior precisão, para conhecer o consumo, o rendimento energético como também para facilitar e/ou padronizar a comercialização. Sendo assim, neste trabalho, levou-se em consideração o fator de conversão 
como um aspecto de qualidade.

Para determinar o fator de conversão, foi tomado como base o volume aparente (Va em st) e volume sólido $\left(\mathrm{Vr} \mathrm{em} \mathrm{m}^{3}\right)$ das diversas pilhas de madeira. Além disso, solicitou-se ao produtor que fizesse uma estimativa do volume de lenha existente na pilha, sendo considerado como volume estimado (Ve em st).

Para facilitar as medições e o cálculo do volume sólido, utilizou-se amostragem em faixa (Figura 1), dividindo-se a pilha em amostras de um metro de largura e sorteando-se uma amostra destas para a cubagem. $\mathrm{Da}$ amostra sorteada, determinaram-se o diâmetro no centro e o comprimento de todos os toretes que ficavam dentro da linha de amostragem. No caso dos toretes que ficavam sob a faixa de amostragem, mediram-se somente os que tinham mais da metade de seu diâmetro para o lado interno da amostra. Dessa forma, o volume sólido ( $\mathrm{Vr}$ ) de madeira da amostra resultou da soma de todos os volumes individuais dos toretes.

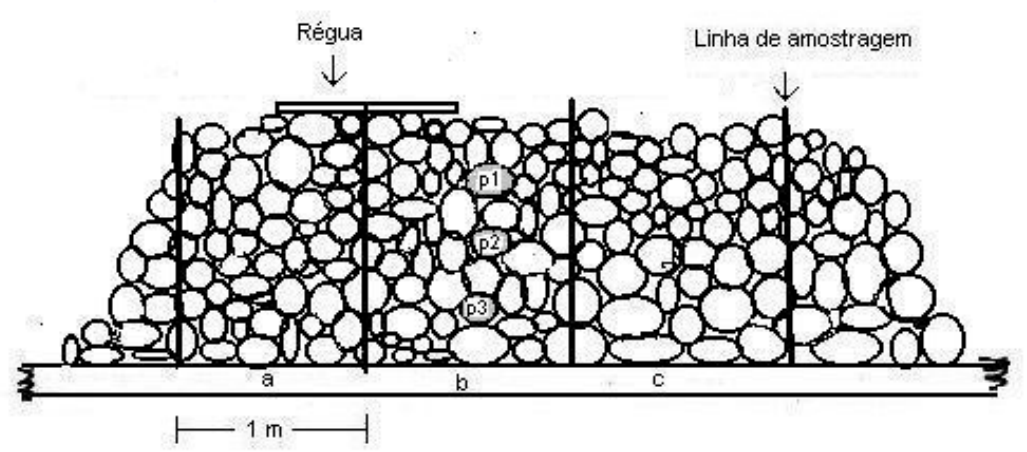

FIGURA 1: Amostragem em faixa para cubagem da pilha de lenha $\left(\mathrm{p}_{1}, \mathrm{p}_{2}\right.$ e $\mathrm{p}_{3}$ são pontos de retirada de toretes; a, b, c são faixas de sorteio para a medição).

FIGURE 1: Sampling in stripe for cubic scaling of the firewood pile (p1, p2 and p3 are points of shortwood seize $\mathrm{a}, \mathrm{b}, \mathrm{c}$ are bands randomly assigned for the mensuration).

Para a obtenção do volume aparente da faixa sorteada (Vafa), mediram-se a altura e a profundidade da pilha (determinada pela média do comprimento dos toretes), já que a largura da faixa foi definida em um metro.

O fator de conversão (FC) foi obtido pela utilização da equação:

$\mathrm{FC}=\frac{\mathrm{Vr}}{\mathrm{Vafa}}$

Posteriormente, mediram-se o comprimento e a altura da pilha, para comparar a estimativa do agricultor com o volume estéreo das pilhas. A altura foi obtida com o auxílio de uma régua de madeira de um metro de comprimento que foi colocada horizontalmente na parte superior da pilha perpendicular aos toretes (Figura 1). A largura da pilha foi obtida pela média do comprimento unitário dos toretes. O cálculo do volume aparente (Va) resultou da multiplicação da largura, altura e comprimento da pilha de lenha.

\section{Massa específica básica ( $\rho_{\text {Bás})}$}

Para determinação da $\rho_{\text {Bás }}$ da madeira, retiraram-se três toretes da parte central de cada pilha, conforme posição mostrada na Figura 1. Um dos toretes $\left(\mathrm{p}_{1}\right)$ foi coletado no terço médio superior, outro $\left(\mathrm{p}_{2}\right)$ na metade da altura e o terceiro $\left(\mathrm{p}_{3}\right)$ no terço médio inferior da pilha. Cada torete foi dividido em duas partes (Figura 2) e de uma delas, escolhida aleatoriamente, retirou-se um disco de $2 \mathrm{~cm}$ de espessura. Os discos, devidamente identificados, foram colocados em saco plástico, para não perderem umidade, e transportados para o Laboratório de Produtos Florestais da UFSM. No laboratório, dividiu-se cada amostra em duas partes, "A" e "B" (Figura 2), para a determinação da massa específica básica e teor de umidade respectivamente. 


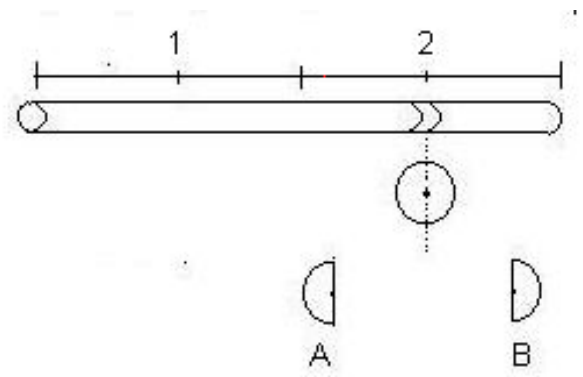

FIGURA 2: Esquema da retirada de amostras dos toretes para a determinação da massa específica básica (A) e teor de umidade (B).

FIGURE 2: Sketch of specimen taken from fuel log for the determination of basic density (A) and moisture content (B).

Para a obtenção da massa específica básica, as amostras foram primeiramente submersas em água até que atingissem peso constante e, posteriormente, mediu-se o volume pelo método do deslocamento por imersão em água. Para tanto, utilizou-se um Becker com capacidade de um litro, preenchido com $800 \mathrm{ml}$ de água, e uma balança eletrônica. Cada corpo de prova foi submerso no líquido, medindo-se a massa d'água deslocada pela madeira a qual foi considerada igual ao seu volume.

Após a obtenção do volume, colocaram-se os corpos de prova em uma estufa a $103^{\circ} \mathrm{C}$ até atingirem peso constante, sendo então pesados novamente, obtendo assim a massa seca correspondente. Tanto a massa seca como o volume foram registrados em formulário específico para cada corpo de prova.

A massa específica básica foi calculada por meio da seguinte equação:

$\rho_{\text {Bás }}=\frac{P o}{V u}$

Em que: $\rho_{\text {Bás }}=$ massa específica básica $\left(\mathrm{g} / \mathrm{cm}^{3}\right) ; \mathrm{Vu}=$ volume úmido $\left(\mathrm{cm}^{3}\right) ; \mathrm{Po}=$ massa seca $(\mathrm{g})$.

\section{Teor de umidade}

Dos mesmos toretes utilizados para a determinação da massa específica, foram retiradas amostras para a determinação do teor de umidade da lenha posta à venda (Figura 2). Já para o teor de umidade da lenha de queima, foram feitas observações em 47 amostras retiradas de pilhas que o agricultor ou o empresário estava prestes a queimar.

$\mathrm{Na}$ determinação do teor de umidade, as amostras foram inicialmente pesadas para a obtenção da massa inicial úmida $(\mathrm{Pu})$, e em seguida colocadas em estufa a $103{ }^{\circ} \mathrm{C}$, até atingirem peso constante, quando então foram novamente pesadas (Po). O teor de umidade na base seca foi calculado por meio da seguinte equação:

$$
\mathrm{Tu}=\left(\frac{\mathrm{Pu}-\mathrm{Po}}{\mathrm{Po}}\right) \bullet 100
$$

Em que: $\mathrm{Pu}=$ massa inicial da peça de madeira $(\mathrm{g}) ; \mathrm{Po}=$ massa final da peça de madeira $(\mathrm{g})$; $\mathrm{Tu}=$ teor de umidade (\%).

No levantamento das amostras, foi anotado o tempo de exposição das pilhas no campo (tempo de secagem), conforme informações dos agricultores, e calculado o tempo de secagem médio empregado pelos agricultores antes da venda e/ou da queima.

\section{Poder calorífico}

Para cálculo do poder calorífico estimado, usou-se uma modificação da equação sugerida por Nock et al (1975): ${ }_{\text {Pci }=\rho_{\text {Bás }}} \bullet\left(4500-52 \bullet\left(\frac{\mathrm{Tu}}{1+\left(\frac{\mathrm{Tu}}{100}\right)}\right)\right) \bullet 0,001162294$

Em que: Pci $=$ poder calorífico inferior $\left(\mathrm{Kwh} / \mathrm{m}^{3}\right) ; \rho_{\text {Bás }}=$ massa específica básica $\left(\mathrm{Kg} / \mathrm{m}^{3}\right) ; \mathrm{Tu}=$ teor de umidade (\%).

Ciência Florestal, v. 13, n. 2, 2003 


\section{RESULTADOS E DISCUSSÃO}

A lenha é o principal produto florestal produzido e consumido na região da Quarta Colônia de Imigração Italiana, RS. Para a avaliação da qualidade da lenha, levaram-se especialmente em consideração o fator de conversão (estéreo para metro cúbico), o teor de umidade, a massa específica básica e o poder calorífico, para as espécies nativas e do gênero Eucalyptus.

\section{Fator de conversão}

As medições feitas pelos agricultores para estimativa do volume (Ve) no momento da venda, geralmente realizadas visualmente sem auxílio de instrumento de medição apropriado, resultam, pelos dados observados (eucaliptos e nativas), numa subestimação do volume real (st). Alguns agricultores (45\% das pilhas de lenha) superestimam o volume, enquanto que outros fazem subestimativas $(55 \%$ das pilhas de lenha). Em média, o volume comercializado é subestimado em aproximadamente $7 \%$. Esse erro de medição leva a uma perda para o agricultor que pode ser amenizada ou mesmo corrigida com a utilização de um instrumento de medição.

O fator de conversão de estéreo para $\mathrm{m}^{3}$ ficou em 0,61 para o gênero Eucalyptus, e 0,56 para as nativas, como mostra a Tabela 1, e são inferiores ao valor médio $(0,67)$ citado por Finger $(1992)$ e por Günther e Lehmann (1982) que o definem na faixa de 0,60 a 0,65 para madeira roliça.

TABELA 1: Número de amostras, média, desvio-padrão, amplitude, valores mínimos e máximos das propriedades estudadas.

TABLE 1: Number of specimen, average, standard deviation, range, minimum and maximum values of the studied properties.

\begin{tabular}{lll|r|r|r|r|r}
\hline Espécie & \multicolumn{1}{c|}{ Propriedade } & $\mathrm{N}$ & Média & \multicolumn{1}{c}{$\mathrm{S}$} & Amplitude & Mínimo & Máximo \\
\hline \multirow{3}{*}{ Eucalipto } & Tu de queima (\%) & 47 & 32,2 & 15,18 & 83,22 & 16,9 & 100,2 \\
& FC & 31 & 0,61 & 0,09 & 0,33 & 0,47 & 0,80 \\
& Tu vendido (\%) & 93 & 74,3 & 35,41 & 128,74 & 20,4 & 149,2 \\
& $\rho_{\text {Bás }}\left(\mathrm{g} / \mathrm{cm}^{3}\right)$ & 93 & 0,44 & 0,05 & 0,24 & 0,29 & 0,53 \\
& Tempo $\left(\mathrm{mês}^{3}\right)$ & 93 & 4,10 & 3,48 & 11 & 1 & 12 \\
\hline \multirow{5}{*}{ Nativas } & FC & 09 & 0,56 & 0,073 & 0,24 & 0,44 & 0,68 \\
& Tu vendido (\%) & 27 & 40,0 & 34,28 & 129,02 & 16,9 & 146,0 \\
& $\rho_{\text {Bás }}\left(\mathrm{g} / \mathrm{cm}^{3}\right)$ & 27 & 0,46 & 0,12 & 0,45 & 0,20 & 0,65 \\
& Tempo (mês) & 27 & 22,67 & 10,30 & 36 & 12 & 48 \\
\hline
\end{tabular}

Em que: $\mathrm{N}=$ número total de amostras; $\mathrm{S}=$ desvio-padrão; $\mathrm{FC}=$ Fator de conversão; $\rho_{\text {Bás }}=$ massa específica básica; Tempo $=$ tempo de exposição da lenha; $\mathrm{Tu}=$ teor de umidade na base seca $(\%)$.

\section{Teor de umidade}

O teor de umidade da madeira é especialmente influenciado pelo tempo de exposição. A Tabela 2 evidencia que o teor de umidade não variou significativamente entre as três diferentes posições de tomada das amostras na pilha (teste $\mathrm{F}$ a $95 \%$ de probabilidade). Esse fato sugere que o uso de uma única amostra por pilha é suficiente para a definição do teor médio de umidade da lenha, nas condições encontradas no presente trabalho. O teor de umidade médio da lenha de eucalipto encontra-se bem acima do ponto de saturação das fibras, o que representa um menor rendimento energético e um maior custo de transporte. Já para as espécies de madeira nativas, o teor de umidade encontra-se próximo ao ponto de saturação das fibras. Nesse caso, a lenha deve ser armazenada em ambiente coberto para evitar a influência das precipitações.

Observa-se, na Tabela 1, que o tempo médio de secagem da lenha de eucalipto empregado na região foi de quatro meses. Para as nativas, esse tempo foi de 22,6 meses. Isso se deve ao costume local de venda quase que imediata da madeira de eucalipto e a demora na venda das nativas. Enquanto a primeira pode ser comercializada com a nota fiscal fornecida pelo produtor, para as nativas é necessário uma série de documentos e taxas impostas pela legislação que, no mínimo, traz morosidade e um grande incômodo para o agricultor. 
Em conseqüência da venda imediata do eucalipto, ainda com um teor de umidade bastante elevado, além do aumento no custo do transporte, há necessidade de armazenamento na empresa até o material atingir a umidade de equilíbrio.

TABELA 2: Resumo da ANOVA para o teor de umidade da lenha nas três posições de coleta de amostras na pilha.

TABLE 2: Summary of ANOVA for the moisture content of the firewood in the three positions of collection of samples in the pile.

\begin{tabular}{ll|ccccccccc}
\hline Espécie & \multicolumn{1}{c}{ Posição } & $\mathrm{N}$ & Média & $\mathrm{S}$ & Mínimo & Máximo & $\mathrm{F}$ & $\mathrm{P}$ \\
\hline \multirow{3}{*}{ Eucalipto } & $1 / 3$ superior & 31 & 72,1 & 32,22 & 20,5 & 129,8 & & \\
& Centro & 31 & 77,1 & 37,85 & 20,4 & 149,2 & 0,212 & 0,809 \\
& $1 / 3$ inferior & 31 & 73,1 & 36,82 & 21,4 & 134,9 & & \\
& Média & 93 & 74,0 & 35,4 & 20,8 & 138,0 & & \\
\hline \multirow{3}{*}{ Nativas } & $1 / 3$ superior & 9 & 44,4 & 39,04 & 19,4 & 146,0 & & \\
& Centro & 9 & 36,9 & 30,7 & 16,9 & 112,7 & 0,109 & 0,897 \\
& $1 / 3$ inferior & 9 & 38,8 & 36,3 & 19,8 & 134,5 & & \\
& Média & 27 & 40,0 & 34,27 & 18,7 & 131,1 & & \\
\hline
\end{tabular}

Em que: $\mathrm{N}$ = número de amostras; $\mathrm{S}=$ desvio-padrão; $\mathrm{F}$ = valor de $\mathrm{F}$ calculado; $\mathrm{P}$ = probabilidade de erro.

No momento da coleta de dados, observou-se que a maioria das pilhas, tanto de nativas como de eucalipto, não apresentavam uma base de isolamento entre o material lenhoso e o solo. Esse contato direto dificulta a secagem da lenha e, quando da exposição prolongada, leva à deterioração da madeira.

Também, pode-se observar, na Tabela 1, que a lenha está sendo queimada com um teor de umidade elevado (32,2\%), e uma amplitude variando de 16,9 a 100,2\% ocorrendo, portanto, perda de energia no momento da queima (Nossek et al., 1988). Há também uma grande amplitude no teor de umidade para a lenha vendida (nativas: mínimo de $16,9 \%$ e máximo de $146 \%$; eucalipto: mínimo de $20,4 \%$ e máximo de 149,2\%). Essa amplitude se deve aos diferentes tempos de secagem empregados pelo agricultor que, em muitos casos, vende imediatamente após o abate das árvores.

Quanto à relação entre o teor de umidade e o tempo de exposição, a equação logaritma mista foi a que melhor representou os dados observados para a madeira de eucalipto (Figura 3). Já para o material lenhoso de nativas, o teste $\mathrm{F}$ não foi significativo ao nível de $95 \%$ de probabilidade para regressão do teor de umidade em razão do tempo de exposição para as equações testadas (linear, logarítmica, inversa, quadrática, cúbica). O número reduzido de amostras utilizadas e, sobretudo, o elevado tempo de exposição da lenha das nativas, podem ter influenciado nesse resultado.

Na Figura 3, observa-se que, nos primeiros meses, a madeira possui muita variação no teor de umidade, ou seja, à medida que o tempo de exposição aumenta diminui rapidamente o teor de umidade.

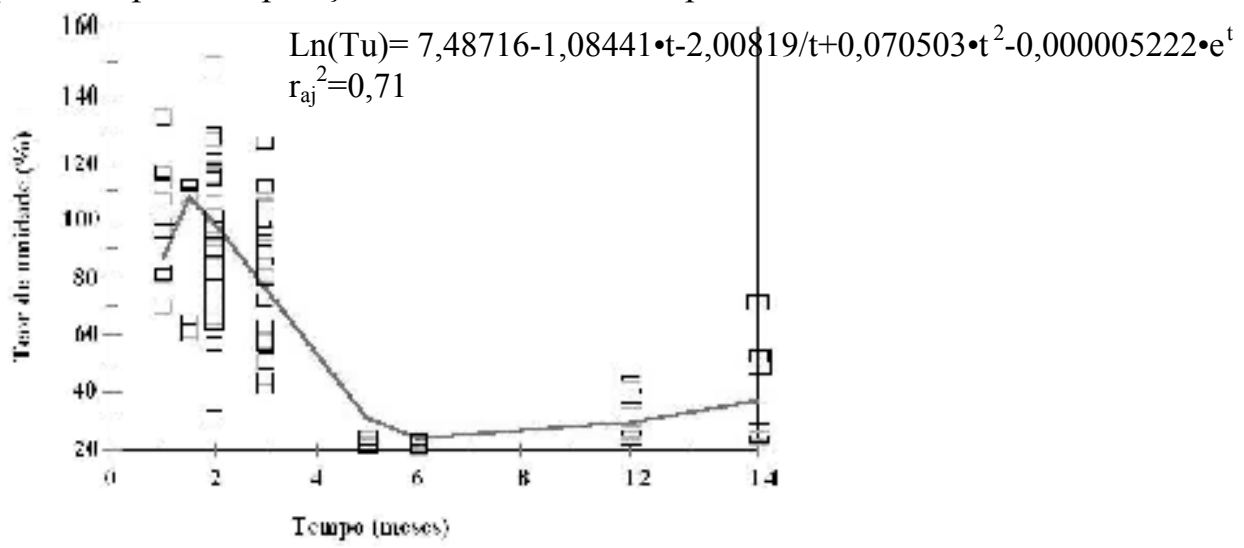

FIGURA 3: Variação do teor de umidade (Tu) em função do tempo de exposição (t) da lenha de eucalipto.

FIGURE 3: Variation of moisture content $(\mathrm{Tu})$ as a function of the time of exposure (t) of the eucalypt firewood. 
O ponto de saturação das fibras é alcançado, aproximadamente, após 5 meses de secagem. Com o passar do tempo, a madeira voltou a adquirir umidade, provocada pelas precipitações e pelo apodrecimento (inicialmente da casca e, posteriormente, do lenho). A alteração no teor de umidade da madeira pode ser atribuída a confecção de pilhas sem cobertura e sem isolamento com o solo. Para evitar esse problema e para viabilizar a secagem da lenha, recomenda-se o seu armazenamento em galpões após 6 meses de exposição ao ar livre, bem como dotar as pilhas de algum tipo de isolamento com o solo.

\section{Massa específica básica}

A determinação da massa específica básica permite a obtenção da estimativa do peso seco da madeira por metro cúbico sólido, ou permite expressar a produtividade da floresta em termos de peso de matéria seca por hectare, importante em termos de rendimento, de transporte, armazenamento e outras operações de controle da matéria-prima.

A $\rho_{\text {Bás }}$ média para o gênero eucalipto foi de $0,44 \mathrm{~g} / \mathrm{cm}^{3}$ e para o grupo das nativas $0,46 \mathrm{~g} / \mathrm{cm}^{3}$ (Tabela 1). A madeira oriunda de eucalipto e de espécies nativas é tida como moderadamente pesada, com massa específica básica entre 0,42 a 0,50 g/ $\mathrm{cm}^{3}$ (Forest Products Laboratory apud Silva, 1984; USDA, 1999), e portanto, em função da massa específica básica, pode-se considerar a lenha da região como de boa qualidade para fins energéticos.

\section{Poder calorífico}

A massa específica tem grande influência no poder calorífico, quando este é expresso em unidades de volume (exemplo $\mathrm{kcal} / \mathrm{m}^{3}$ ), procedimento comumente adotado no dimensionamento de instalações de combustão. Outro fator que influencia o poder calorífico da madeira é o teor de umidade, pois quanto maior a umidade, maior é a quantidade de energia necessária para evaporação da água.

Supondo que a umidade de equilíbrio de $17 \%$ da região de estudo seja a mesma de Santa Maria, pode-se estimar a produção de energia para as madeiras de eucalipto $\left(\rho_{\text {Bás }} 0,44 \mathrm{~g} / \mathrm{cm}^{3}\right)$ e nativas $\left(\rho_{\text {Bás }} 0,46\right.$ $\mathrm{g} / \mathrm{cm}^{3}$ ) em, respectivamente, 1915 e $2.002 \mathrm{Kwh} / \mathrm{m}^{3}$. No entanto, o teor de umidade de queima foi de $32,2 \%$ levando o aproveitamento de energia por metro cúbico a aproximadamente 1.654 e 1.729 Kwh respectivamente para eucalipto e para nativas. Perde-se, em média, por metro cúbico de lenha, 13,6\% da energia em razão da queima com teor de umidade inadequado. Considerando-se que o consumo de lenha da região em 1999 que foi de $4679 \mathrm{~m}^{3}$ (Gatto, 2002), verifica-se que o desperdício estimado ficou em torno de $636 \mathrm{~m}^{3}$. Como o preço médio da lenha comercializada na região foi de $\mathrm{R} \$ 18,35 / \mathrm{m}^{3}$, o prejuízo financeiro estimado é de $\mathrm{R} \$ 11.677$.

Levando em consideração que, em alguns casos, a lenha é queimada com teor de umidade de 50\%, significa que um $\mathrm{m}^{3}$ de lenha de eucalipto pode produzir apenas $1.415 \mathrm{kwh}$, com uma perda de $26 \%$ de energia por $\mathrm{m}^{3}$. Alguns empresários queimam lenha com teor de umidade em torno de $100 \%$ o que gera uma perda de energia ainda maior.

\section{CONCLUSÕES}

Com base nos resultados deste estudo realizado na região da Quarta Colônia de Imigração Italiana, $\mathrm{RS}$, pode-se concluir que:

A massa específica básica da lenha oscilou entre $0,44 \mathrm{~g} / \mathrm{cm}^{3}$ para eucalipto e $0,46 \mathrm{~g} / \mathrm{cm}^{3}$ para nativas, o que as inclui entre as madeiras levemente densas.

O fator de conversão de estéreo para metro cúbico, que serve para estimar o volume de madeira sólida, foi, respectivamente, de 0,61 e 0,56 para a lenha de eucalipto e de nativas.

O poder calorífico estimado para a umidade de equilíbrio média da região foi, respectivamente, 1915 e $2002 \mathrm{Kwh} / \mathrm{m}^{3}$ para a madeira de eucalipto e de espécies nativas. Como a lenha é queimada a $32 \%$ de umidade, ocorre, em média, uma perda de $13,6 \%$ na energia produzida por tais madeiras. 


\section{AGRADECIMENTOS}

Os autores agradecem ao Projeto "Floresta Colonial", convênio entre a Universidade Federal de Santa Maria e a Universidade Rural de Viena - Áustria, pelo financiamento parcial desta pesquisa.

\section{REFERÊNCIAS BIBLIOGRÁFICAS}

BRASIL. Ministério de Minas e Energia. Balanço energético nacional, Brasília, 2000. 154p.

CUNHA, P. S. C.; PONTES, C. L. F.; CRUZ, I. de A.; CABRAL, M. T. de F. D.; NETO Z. B. da C.; BARBOSA, A. P. R.. Estudo químico de 55 espécies lenhosas para geração de energia em caldeiras. In: ENCONTRO BRASILEIRO EM MADEIRAS E EM ESTRUTURAS DE MADEIRA, 3., 1989, São Carlos. Anais ... São Carlos, 1989. v.2, p. 95-121.

FAO. Organização das Nações Unidas para a Alimentação e a Agricultura. La madera: combustible para promover el desarrollo. Roma, 1987. 19 p.

FAO. Organização das Nações Unidas Para a Alimentação e a Agricultura. Relatório da consulta técnica sobre a pesquisa e desenvolvimento da energia com base na madeira na África. Roma, 1985. $25 \mathrm{p}$.

FARINHAQUE, R. Influência da umidade no poder calorífico da madeira de Bracatinga (Mimosa scrabella, Benth) e aspectos gerais de combustão. Curitiba: FUPEF, 1981. 14p. (Série Técnica).

FERREIRA, M. C.; FERNANDES, P. S.; SARAIVA FILHO, J. C. Variação na umidade da madeira de eucalipto, estocada em pátio industriais. In: CONGRESSO FLORESTAL BRASILEIRO, 4., 1982, Belo Horizonte. Anais... Belo Horizonte: SBS/IBDF/CNPq/FINEP, 1983. p 779-781.

FERNANDES, P. S.; SARAIVA FILHO, J. C.; FERREIRA, M. C.. Contração volumétrica da madeira roliça de Eucalyptus saligna Smith em estoque. In: CONGRESSO FLORESTAL BRASILEIRO, 4., 1982, Belo Horizonte. Anais... Belo Horizonte: SBS/IBDF/CNPq/FINEP, 1983. p. 774-775.

FINGER, C. A. G.. Fundamentos de biometria florestal. Santa Maria: UFSM/CEPEF/FATEC, 1992. 269p.

FLORESTA COLONIAL. Convênio UFSM/BOKU. Produção de madeira para fins energéticos. Santa Maria, 2000.

GATTO, D. A. Avaliação quantitativa e qualitativa da utilização madeireira na região da Quarta Colônia de imigração italiana no Rio Grane do Sul. 2002. 108 p. Dissertação (Mestrado em Engenharia Florestal) - Universidade Federal de Santa Maria, Santa Maria, 2002.

GRAUER, A.; KAWANO, M.. Uso de biomassa para produção de energia. Boletim Informativo da Bolsa de Reciclagem, v.1, n. 5. nov/dez., 2001. Disponível em: <webmaster@ambientebrasil.com.br/ composer...tml\& conteudo=./energi/biomassa_vant.html>. Acesso em: 24 mar. 2002.

GÜNTHER, B.; LEHMANN, G. Umrechnunopzahlen für Holz: Probleme, Fahten, Fusammenhänge, Beiträge für die Forstcrirtschafl, 1982. p. $181-186$.

IPF. Proposta de portaria do INMETRO prevê a proibição da utilização do estéreo em 2010. IPF Notícias, p. 11, jun./ago., 1999.

KOLLMANN, F.F.P.; CÔTÉ Jr, W. A.; Principles of wood science and technology: I. solid wood. New York: Springer Velang, 1968. 592 p.

MARABOTO, M. T.; CUNHA, P. S. C.; PONTES, C. L. F.; CRUZ; I. de A.; NETO; Z. B. da C.. Poder calorífero e pirólise de dez espécies florestais da Amazônia Brasileira - Peruana. In: ENCONTRO BRASILEIRO EM MADEIRAS E EM ESTRUTURAS DE MADEIRA, 3., 1989, São Carlos. Anais ... São Carlos, 1989. v. 3, p. 7-27.

NOCK, H. P.; RICHTER, H. G.; BURGER, L. M. Tecnologia da madeira. Curitiba: UFPR- Setor de Ciências Agrárias, Departamento de Engenharia e Tecnologias Rurais, 1975. 200p.

NOSSEK, E.; JONAS, A.; SCHÖRGHUBER, F.; HOLZ, H. Ein Energieschwerpunkt des Landes Niederösterreich. Wien, 1988.

PÖCKL, M. Anreize und Hemmfaktoren für ein forstwirtschaftliches Engagement von Landwirten in der Region Ivorá in Südbrasilien. Wien: BOKU, 2000. 150p. Diplomarbeit Universität für Bodenkultur, Wien, 2000.

SILVA, J. C. Parâmetros de densidade na qualidade da madeira. Piracicaba: USP, 1984. 82 p. Seminário apresentado na disciplina Qualidade da Madeira para Celulose e Papel.

SILVA, L.B.X; NETO, F.R.; TOMASELLI, I. Estudo comparativo da produção de biomassa para energia entre 23 espécies florestais. In: CONGRESSO FLORESTAL BRASILEIRO, 4, 1982, Belo Horizonte. Anais... Belo Horizonte : SBS/IBDF/CNPq/FINEP, 1983. p. 872-878. 
USDA. United States Department of Agriculture. Forest Service. Wood Handbook: wood as an engineering material. Madison : Department of Agriculture, 1999. $463 \mathrm{p}$.

VALE. A.T.; BRASIL, M.A.M.; CARVALHO, C.M.; VEIGA, R.A.A. Produção de energia do fuste de Eucalyptus grandis Hill Ex-Maiden e Acacia mangium Wolld em diferentes níveis de adubação. Cerne, v. 6, n. 1, p.83-88, 2000.

ZAKIA, M. J. B.; VERSLYPE, C. G.; PAREYN, F.G.; SENA, C. M.; GARIGLIO, M.A. O consumo de energéticos florestais no Rio Grande do Norte. Natal, 1990. 40 p. 